Original Research

\title{
Determinants of Nutritional Status Among Pregnant Women: a Transcultural Nursing Approach
}

\section{Ni Ketut Alit Armini, Nurul Hidayati, and Tiyas Kusumaningrum}

Faculty of Nursing, Universitas Airlangga, Surabaya, East Java, Indonesia

\begin{abstract}
Introduction: Pregnant women experiencing poor nutritional status remains a problem which is still commonly found in Surabaya. Poor nutritional status is one of the causes of increased mortality in pregnant women. The mother's education and occupation, family income, number of children, and family shape are associated with the incidence of nutritional status in pregnant women. The purpose of this study was to explain the factors related to the nutritional status of pregnant women based on transcultural nursing theory.
\end{abstract}

Methods: his study uses a cross-sectional design. The population were pregnant women at the Public Health Center Tanah Kali Kedinding Surabaya Indonesia, 104 respondents were selected using a consecutive sampling technique. The independent variables were technological, religious, family support, cultural values, political \& legal, economic, and educational, while the dependent variable was the incidence of nutritional status in pregnant women. The data was obtained using questionnaires and mid upper arm circumstance (MUAC) measurements. The data was analyzed using the Spearman rho test.

Results: There was a relationship between technological $(\mathrm{p}=0.001 ; \mathrm{r}=0.332)$, family support ( $p=0.000 ; r=0.379)$, cultural values ( $p=0.000 ; r=0.702)$, political \& legal $(p=0.000 ; r=0.387)$, economic $(p=0.031 ; r=0.212)$, and educational $(p=0.020$ $; r=0.228$ ) factors with nutritional status in pregnant women.

Discussion: Technological, family support, cultural values, political \& legal, economic, and educational factors influenced the nutritional status of pregnant women. The cultural factor was the most dominant in influencing the nutritional status of pregnant women.

\section{ARTICLE HISTORY}

Received: 13 August, 2020

Accepted: November 7, 2020

\section{KEYWORDS}

women; pregnant; health; nutritional; transcultural

\section{CONTACT}

Ni Ketut Alit Armini $\triangle$ k.alita@fkp.unair.ac.id $\equiv$ Faculty of Nursing, Universitas Airlangga, Surabaya, East Java, Indonesia

Cite this as: Armini, N. K. A., Hidayati, N., \& Kusumaningrum, T. (2020). Determinants of Nutritional Status Among Pregnant Women: a Transcultural Nursing Approach. Jurnal Ners, 15(2). 214 - 221. doi:http://dx.doi.org/10.20473/jn.v15i2.21388

\section{INTRODUCTION}

In Indonesia, the prevalence of GDM is around 14\% of all pregnant women, and $10-25 \%$ of the total cases handled are undiagnosed or diagnosed GDMs (Dewi et al., 2020). According to Medical Record Department, Sardjito Hospital of Yogyakarta, the prevalence of GDM in Indonesia is approximately 1,93,6 on inpatient disease index of GDM in the last 10 years from 2012-2013.
Many pregnant women experience nutritional problems, especially malnutrition such as a chronic energy deficiency (Blondin \& LoGiudice, 2018). Chronic energy deficiency (CED) is one of the causes of increased mortality in mothers (Bhutta et al., 2008). Many factors affect the incidence of CED, one of which is a less diverse diet and fewer portions (Rubina Shaheen, 2016). Chakona \& Shackleton (2019) stated that the causes of a lack of variety in food intake consumed by mothers included the taboo culture of food. In some regions in Indonesia there are 
still many pregnant women who adhere to the belief in abstinence from consuming certain types of food that are required during pregnancy (Triharini, Nursalam, et al., 2018). The culture affects all aspects of life including health (Diana et al., 2019). In addition to cultural factors, there are also several factors related to the health of pregnant women, namely education, income, family members (Serbesa, Iffa, \& Geleto, 2019), type of residence, mother's age, and parity (Islam, Islam, Bharati, Aik, \& Hossain, 2016).

The results of a nutritional status survey in Indonesia in 2016 amounted to $16.2 \%$ of pregnant women experiencing CED. This shows that there is an increase in CED problems in pregnant women, as much as $2.9 \%$ from the previous year, and in the same year the intake of nutritional consumption is still relatively low, at $26.3 \%$ of pregnant women whose consumption is good and meets energy adequacy (Kemenkes, 2017). The results of the Demographic Health Survey (DHS) in 2018 recorded that the proportion of pregnant women aged 15-49 years with upper arm circumference $<23.5 \mathrm{~cm}$ was $17.3 \%$. The amount of pregnant women who experienced CED in East Java was $19.59 \%$ and Surabaya City was ranked the second-highest among other districts and cities at 33\%. Data obtained from the Health Report Surabaya City in 2018 of 681 mothers who had a pregnancy check at the Tanah Kali Kedinding Public Health Center found 145 (21.3\%) pregnant women who experienced CED. Based on a preliminary study conducted on 10 February 2020 through interviews with 10 pregnant women who had a pregnancy check at the Policlinic of Public Health Center Tanah Kali Kedinding, it was found that $20 \%$ of pregnant women experience poor nutritional status. Based on interviews, $40 \%$ of pregnant women still believe in food restrictions, $50 \%$ of pregnant women have less family support, and all pregnant women say they do not know about government policies related to nutrition fulfilment programs for pregnant women.

Beliefs about the culture that can affect health in Indonesia are still very rich and varied. Some people still believe in the culture of food prohibition for pregnant women, which can accidentally eliminate some important nutrients that should be consumed by pregnant women (Parmar, Khanpara, Kartha, Resident, \& Shah, 2013). Food restrictions are believed to be the cause of why mothers become malnourished (Ipa, Prasetyo, \& Kasnodihardjo, 2016). The problem of malnutrition experienced by the mother during pregnancy has serious consequences for the mother and the baby in both the short and long term. Short-term effects on the mother can cause a risk of abnormalities and complications, namely anemia, bleeding, and cause labor difficulties and bleeding after delivery. In infants malnutrition can cause low birth weight and preterm birth, which has a long-term impact as in the future the child will be at risk of experiencing mental and physical disorders during growth and development (Demelash, Id, \& Dadi, 2019).
The cultural dimension of pregnant women in the city of Surabaya is still quite strong, therefore an analysis of the problem using the transcultural approach is needed. Transcultural nursing was chosen because it depicts humans who are not separated from cultural backgrounds and social structures, views, history and environmental context. The purpose of this study was to analyze the factors related to nutritional status in pregnant women based on transcultural nursing theory.

\section{MATERIALS AND METHODS}

This research was a phenomenological approach qualitative research. Data collection was carried out through in-depth interviews with a voice recorder and field notes. Participants were selected based on research needs with the principle of appropriateness and adequacy. Participants in this research were mothers who delivered to a maximum of 1 year with a history of GDM. The data collection was finished in the twelve participant when the categorization of data was saturated. In addition, the availability of time and resources in research is also taken into consideration in ending data collection. This research instrument was the researchers themselves. Purposive sampling technique with sampling criterion was used. The inclusion criteria in this study were 1). Mothers who have given birth for a maximum of the last 1 year and were treated at Dr. Sardjito with a history of DMG. 2) Living in the Special Region of Yogyakarta Province. 3). The maternal age of delivery was less than 18-45 years. 4). Maternal gestational age was less than 32 weeks and more than 40 weeks. 5). Willing to become a participant by agreeing the informed consent. The exclusion criterion was poor pregnancy outcome (stillbirth and severe defects). Data analysis used the Colaizzi method. The inclusion of additional steps were 1). Transcribing all the subjects' descriptions. 2). Extracting significant statements (statements that directly relate to the phenomenon under investigation). 3). Creating formulated meanings. 4). Aggregating formulated meanings into theme clusters. 5). Developing an exhaustive description (that is, a comprehensive description of the experience as articulated by participants). 6). Additional step was researcher's interpretative analysis of symbolic representations from the articulation of the symbolic representation (which occurred during participant interview). 7). Identifying the fundamental structure of the phenomenon. 8). Returning to participants for validation (Edward \& Welch, 2011). Data were collected between December 2013 and February 2014. Nursing theory of maternal role attainment (Shrestha et al., 2019) was used as a reference to analyse life experience of mother with GDM. The validity of the data in this research was tested and included the credibility, dependability, and conformability. The study was declared to have 
passed the ethical review by the Research Ethics Committee, Faculty of Medicine, Gadjah Mada University.

\section{Method}

The design of this study was descriptive-analytic. A cross-sectional study approach was used, whereby the researcher measures the data of the independent and dependent variables one at a time.

\section{Population, Samples, and Sampling}

The population in this study was all pregnant women who visited ante natal care in the working area of the Public Health Center Tanah Kali Kedinding during the last 3 months from December 2019 to February 2020 , totaling 260 pregnant women. Samples were selected using a consecutive sampling technique. 104 pregnant women were found to fit the inclusion criteria, namely pregnant women who had a mother and child health book and exclusion criteria, namely pregnant women with mental disorders.

\section{Variable}

The independent variables in this study are the use of technology, religiosity, family support, cultural, political \& legal values, economics, and education as seven dimension of transcultural nursing. The dependent variable is the nutritional status of pregnant women.

\section{Measurement}

The instruments used in this study were a questionnaire and MUAC measurement using tape to determine the nutritional status of pregnant women based on the mother and the child's health book. The questionnaire in this study was taken and modified from the (Yunitasari, Pradanie, \& Susilawati, 2016) research questionnaire. The questionnaire consisted of 38 questions about the use of technology, including access to print and electronic media, access to health services, access to infrastructure, religiosity, including ways of looking at grace, ways of treatment or religious habits that have a positive effect on health, family support including emotional support, information support, facilities, cultural values including perceptions about health workers, cultural references, beliefs related to meeting nutritional needs, maternal habits, political \& legal aspects including knowledge of regulations and policies, attitudes towards regulations and policies, economic factors including family income, and education aspects including the mother's education. The questionnaire was given in the form of close-ended questions, namely dichotomy questions (technology and political, \& legal utilization questionnaire) and the questions were measured using a Likert scale (questionnaire of religiosity, family support, cultural values). Pregnant women are said to have a good value in seven factors in the transcultural nursing dimension if the score is $>50 \%$ and less if the value scores $\leq 50 \%$. The nutritional status of pregnant women is based on the measurement of the midupper arm circumference (MUAC) listed in the MCH Handbook. The category of nutritional status was less if the MUAC was $<23.5 \mathrm{~cm}$, the nutritional status was good if the MUAC was $>23.5 \mathrm{~cm}$.

This questionnaire was tested for validity and reliability on 21 pregnant women with different populations and obtained valid results from all questionnaires.

\section{Procedure}

Conducting the research began with obtaining permission from the relevant parties. Researchers collected data from 1-29 April 2020 using two methods, the first before the emergence of the Covid19 outbreak. The researcher collected data at the Public Health Center Tanah Kali Kedinding Surabaya every day mother, specifically from child health services (Monday-Wednesday). For the second method, after the Covid-19 pandemic emergency was announced, the researcher collected data online through an online form by contacting each respondent using the telephone numbers obtained from the Public Health Center. The researcher contacted the respondents and explained to the respondent the purpose, benefits of the study and obtained informed consent from the respondent. The researcher explained to the respondent how to fill out the questionnaire. The researcher checked the questionnaire had been completed before it was collected by the researcher.

\section{Analysis}

The collected data were analyzed using the Spearman rho statistical test with a significance level of $p<0.05$. If the results of $\mathrm{p}<0.05, \mathrm{H} 1$ is accepted, meaning that there is a significant relationship between the independent variable and the dependent variable. If $\mathrm{p} \geq 0.05$ then $\mathrm{H} 0$ is accepted, meaning that there is no relationship between the independent variable and the dependent variable. The strength of the variable relationship is expressed in a positive coefficient if $r=$ +1 , meaning there is a very strong positive relationship, if $r=-1$ this means there is a very strong negative relationship, and if $r=0$ then there is no relationship.

\section{Ethical Clearance}

This research was conducted following research ethics and received a certificate of ethics from the Ethics Committee of the Faculty of Nursing, Universitas Airlangga with no. 1944-KEPK.

\section{RESULTS}

Socio-demographic characteristics (Table 1) show that the majority of respondents and husbands of respondents aged 20-35 years were 88 (84.6\%) and 
Table 1. Demographic Distribution of Respondents ( $n=104)$

\begin{tabular}{|c|c|c|c|}
\hline $\begin{array}{l}\text { Demographic Sub } \\
\text { Characteristics }\end{array}$ & Category & Frequency (f) & Percentage (\%) \\
\hline \multirow{3}{*}{$\begin{array}{l}\text { Mother's age } \\
\text { (years) }\end{array}$} & $<20$ & 3 & 2.9 \\
\hline & $20-35$ & 88 & 84.6 \\
\hline & $>35$ & 13 & 12.5 \\
\hline \multirow{3}{*}{$\begin{array}{l}\text { Husband's age } \\
\text { (years) }\end{array}$} & $<20$ & 2 & 1.9 \\
\hline & $20-35$ & 82 & 7.8 \\
\hline & $>35$ & 20 & 19.2 \\
\hline \multirow{3}{*}{$\begin{array}{l}\text { Mother's } \\
\text { occupation }\end{array}$} & Housewife & 75 & 72.1 \\
\hline & Private employee & 26 & 25 \\
\hline & etc. & 3 & 2.9 \\
\hline \multirow{4}{*}{$\begin{array}{l}\text { Husband's } \\
\text { occupation }\end{array}$} & Civil servants & 7 & 6.7 \\
\hline & Private employee & 70 & 67.3 \\
\hline & Entrepreneur & 16 & 15.4 \\
\hline & etc. & 11 & 10.6 \\
\hline \multirow{4}{*}{$\begin{array}{l}\text { Number of } \\
\text { children }\end{array}$} & 0 & 34 & 32.7 \\
\hline & 1 & 35 & 33.7 \\
\hline & 2 & 22 & 21.2 \\
\hline & $\geq 3$ & 13 & 12.5 \\
\hline \multirow{2}{*}{ Family form } & Nuclear family & 43 & 41.3 \\
\hline & Extended family & 61 & 58.7 \\
\hline \multirow{4}{*}{$\begin{array}{l}\text { Number of family } \\
\text { members }\end{array}$} & 2 & 11 & 10.6 \\
\hline & 3 & 13 & 12.5 \\
\hline & 4 & 21 & 20.2 \\
\hline & $\geq 5$ & 59 & 56.7 \\
\hline
\end{tabular}

Table 2. The relationship between the use of technology, religiosity, family support, cultural values, political \& legal, economics, education and nutritional status of pregnant women $(n=104)$

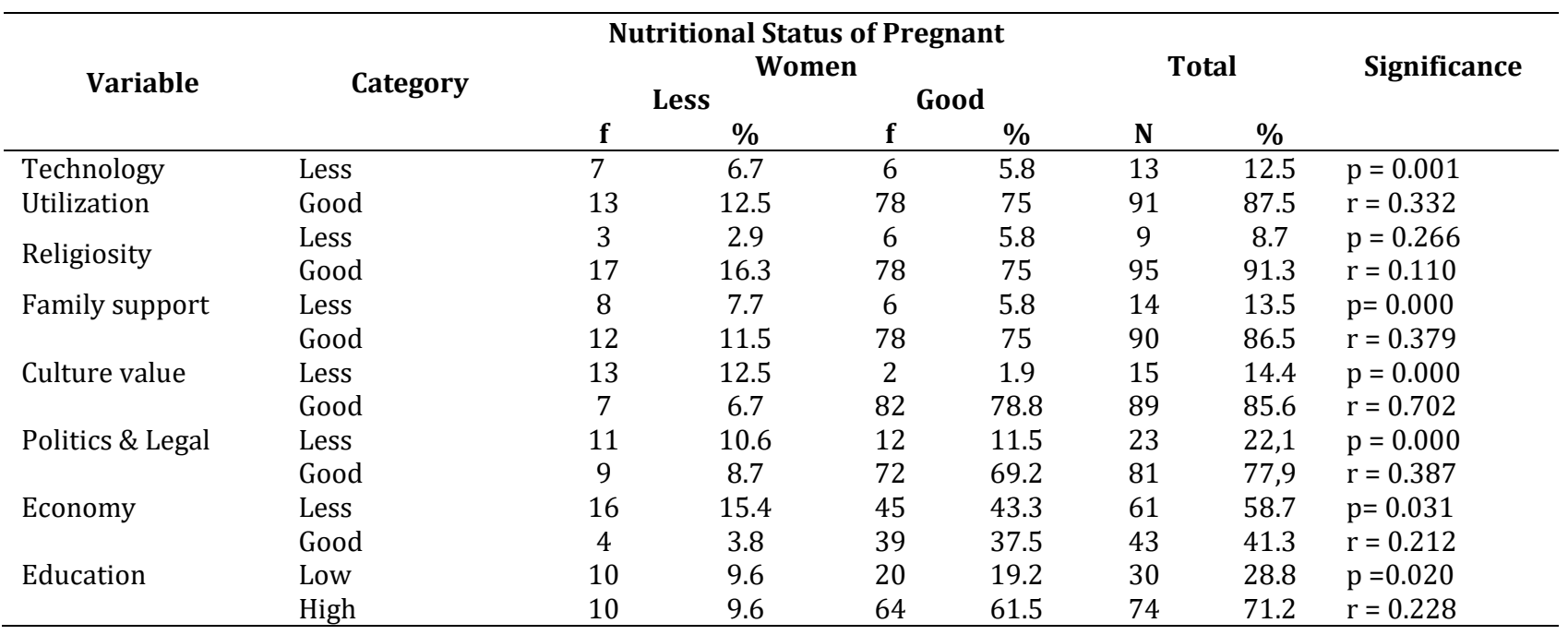

$82(78.8 \%)$, but there were still some pregnant women who were less than 20 years old and over 35 years. Maternal age $<20$ years or $>35$ years is a highrisk age to be able to experience CED and tends to give birth to LBW babies. In the occupational category, 75 (72.1\%) respondents were housewives, and for 70 $(67.3 \%)$ the husband's work was private. 35 (33.7\%) -risk age to be able to experience CED and tends to give birth to LBW babies. In the occupational category, $75(72.1 \%)$ respondents were housewives, and for $70(67.3 \%)$ the husband's work was private. $35(33.7 \%)$ respondents had 1 child. Mothers with a high number of births can experience various health problems for both mothers and their babies. 61 
(58.7\%) respondents lived with their large family. Large families can influence the culture and habits of mothers during pregnancy, mothers who live with large families tend to obey and hold fast the beliefs which family and ancestors have taught for generations.

Table 2 shows that most of the pregnant women who were in the good categories in utilizing technology, religiosity, family support, cultural values, legal politics, and education are in good nutrition status. It appears that some mothers' economic status lacks good nutritional status. Components of transcultural nursing related to the nutritional status of pregnant women include technology utilization factors $(\mathrm{p}=0.001)$, family support $(\mathrm{p}=0.000)$, cultural values $(\mathrm{p}=0.000)$, political and legal $(p=0.000)$, economy $(p=0.031)$, education $(p=0.020)$. However, religiosity is not related to the nutritional status of pregnant women.

\section{DISCUSSION}

The nutritional status of pregnant women is one indicator by which to measure the nutritional status of the community. If nutritional consumption for pregnant women is not balanced with the needs of the body this can cause nutritional deficiencies. Nutrient deficiencies in pregnant women are still very high in Indonesia, this is indicated by the high MMR caused by CED during pregnancy (MOH RI, 2009). The results of this study indicate that there are still some pregnant women (19.2\%) experiencing poor nutritional status, it shows that there are still some pregnant women who have poor nutritional status with a MUAC less than $23.5 \mathrm{~cm}$. Transcultural nursing was depicts humans who are not separated from cultural backgrounds and social structures, views, history and environmental context. The seven transcultural components of nursing studied include technology, religiosity, family support, cultural, political \& legal values, economics, and education(Leininger \& Mcfarland, 2002).

The data shows that there is a relationship between the use of technology with nutritional status in pregnant women. Most pregnant women in the good category for technology use tend to have good nutritional status. Similar research shows that information obtained by pregnant women from print or electronic media will increase the mother's knowledge about the importance of consuming nutritious food so that it can motivate mothers to regularly consume healthy and nutritious food(Triharini, Armini, \& Nastiti, 2018).

The majority of pregnant women in this study were housewives. Housewives spend more time at home. This can be used to utilize technology appropriately to find information about nutritional status and proper food during pregnancy and can also be used to make nutritious foods by utilizing modern equipment (such as blenders, refrigerators, etc.) to meet their nutritional needs.
The education level of the majority of pregnant women also influences the appropriate utilization of technology in pregnant women. According to (Krishnaswamy, 2001), the use of technology is strongly influenced by human resources or the human brain. The higher the level of education, the better the mastery and use of technology; this will have an impact on the health of the nutritional status of mothers during pregnancy.

Almost all pregnant women in the category of good religiosity have a good nutritional status. Based on the results of the analysis, there is no relationship between religiosity and nutritional status in pregnant women. This is because almost all pregnant women have the same beliefs, causing no difference in the religious level of pregnant women. Fitriani (2016) states that a person is said to have good religiosity by not only claiming to have religion (having religion), but also must have religious knowledge, religious beliefs, observe religious rituals, and behavior (religious morality). This has been seen in the majority of pregnant women. The results of this study also showed that many aspects of a pregnant mother's religiosity were positive. Almost all pregnant women trust and are always grateful for the pregnancy they are experiencing, always pray for their health and the prospective baby, and follow the religious community's "majelis ta"lim" and want to share with others in need. This shows that pregnant women are already good at applying religious values related to the health of their nutritional status.

Although one's religiosity also influences the perspective of health, one's belief in a particular religion does not have a significant impact on nutritional status during pregnancy. Almost all pregnant women have a good level of religiosity, but not all have good nutritional status, there are still pregnant women in the category of malnutrition. This is because several other factors can have an influence, such as utilizing health services and not paying attention to the religious aspects they believe, but rather paying attention to other factors such as beliefs in the cultural values they hold.

Family support is one of the factors related to nutritional status in pregnant women. There is a relationship between family support and nutritional status in pregnant women. The majority of pregnant women get positive family support and have a good nutritional status. Pregnant women who get positive family support get the highest support in the emotional support aspect of the family, motivating pregnant women to consume nutritious food.

According to (Triharini, Nursalam, et al., 2018) family support involves meaningful social relationships and can have a positive influence on the recipient. Lack of family support can cause pregnant women to be negative in determining health care for themselves, especially related to the fulfilment of nutritional intake during pregnancy. Negative family support in this study shows that families rarely listen 
to the complaints of pregnant women, forbid the consuming of some food, do not allow them to be seen by health workers, and do not provide costs to go to health workers.

Family support is also seen as a reinforcing factor for the formation of health behaviors (Alit Armini, Tristiana, \& Ose Tokan, 2017). This finding shows that information about nutritional status in pregnant women also involves the family, so it can be a good supporting component for pregnant women.

There is a relationship between cultural values and nutritional status in pregnant women. Pregnant women with good cultural value categories have good nutritional status. Nearly half of pregnant women still have some incorrect beliefs about culture related to fulfilling nutrition during pregnancy (taboo culture). This result is supported by research Parmar et al., (2013) which shows that there are still many pregnant women who believe in old, unscientific culture during pregnancy that can affect the nutrition of pregnant women.

Culture is a view of the life of an individual or group concerning the values, beliefs, norms, patterns, and practices that are learned, shared and passed down between generations (Diamond-Smith, Gupta, Kaur, \& Kumar, 2016). This is evidenced by the general data of pregnant women, the majority of whom live with large families, so the influence of the previous generation is still strong in influencing the daily activities of pregnant women. However, in this study, some pregnant women did not believe in a culture related to pregnancy. This is done as a form of adherence to the advice and suggestions from parents because they are afraid of karma if they are not obedient to what is ordered by their parents.

The results of this study also showed that there were still some pregnant women who had negative cultures and habits. Negative cultural values are beliefs that do not lead or refer to health (Yunitasari, Pradanie \& Susilawati, 2016). Some pregnant women also still smoke. They had the habit of smoking before they became pregnant, so the habit was continued even though they were pregnant. (Nurdin, Hadju, Ansariadi, Zulkifli, \& Arundhana, 2018) mentioned that there are several causes of pregnant women smoking, namely the habit before pregnancy, the desire to smell the smoke of cigarettes during pregnancy, and that they will feel satisfied when smoking; pregnant women who smoke also have the support of their husbands. Negative behavior of pregnant women is supported by the environment, which is a unifying tool in society.

There is a relationship between politics \& law with nutritional status in pregnant women who work in the Public Health Center Tanah Kali Kedinding, Surabaya Indonesia. Most of the pregnant women in both categories had political and legal knowledge. A similar study by Muttaqin (2018) also shows that knowledge of policies and regulations possessed by pregnant women is directly proportional to the attitude towards fulfilling nutrition in their infants. Politics \& law in this study related to the knowledge of pregnant women is related to the allocation of funds and balanced nutritional foods that are recommended during pregnancy.

The majority of pregnant women understand the rules and policies on the recommendation of balanced nutrition. This shows that the socialization of regulations and policies related to nutrition status carried out in the working area of the Tanah Kali Kedinding Health Center is good. However, it is suspected that socialization has not reached all pregnant women. This is because there are still some pregnant women who do not understand the rules and policies regarding balanced nutrition.

More than half of pregnant women have less economic status. The results of this study also showed that pregnant women in the undernutrition category lived in households with low monthly family income. There is a relationship between economic factors and nutritional status in pregnant women. Economic factors were identified as important predictors related to the nutritional status of pregnant women.

Similar research conducted by Hundera et al., (2015) shows that monthly income is significantly related to the nutritional status of pregnant women. Family economic status is a prerequisite for getting adequate food intake and improving nutritional status for pregnant women. More than half of pregnant women have an income above the minimum wage of $>$ Rp.4,200,000 and are in the category of good nutritional status. Economic status is closely related to the income obtained; high income is usually the amount and type of food consumed, which will also be higher (Triharini, Armini, et al., 2018).

Most pregnant women work as housewives. This causes pregnant women to not have a fixed income every month, which can help their husbands to find additional sources of income. If the source of income in the family is low, it will affect the fulfilment of primary needs, one of which is nutritious food which will later have an impact on the family's health status (Adams et al., 2018)

There is an equal number of pregnant women with poor nutritional status categories with low education and pregnant women with good nutritional status categories with higher education. There is a relationship between maternal education and nutritional status in pregnant women. Education plays an important role in the nutritional status of pregnant women, as this education influences nutrition and is associated with the ability of pregnant women to make better decisions for themselves and their children. A study at Miso Health Center, Ethiopia shows that the prevalence of malnutrition is much higher among pregnant women with low education (Serbesa et al., 2019). 
Pregnant women with a high education will be more careful about what they eat than those with low education. Other research by Chandra et al., (2019) shows that there is a relationship between the level of education, with the incidence of nutritional status in pregnant women associated with anemia; Renjani \& Misra (2017) also shows that there is a relationship between the level of education with the incidence of CED. Pregnant women with low education have a 13.2 times greater chance of experiencing CED compared to pregnant women with high education.

Person's knowledge is influenced by several things, one of which is education (Lee, Newton, Radcliffe, \& Belski, 2018). The higher the education, the easier it will be to receive information from outside. However, this does not mean that a person with low education is low in knowledge either. Although some pregnant women have a primary school education and graduate from a junior high school, they have good nutritional status during pregnancy. This study also shows that there are a small proportion of pregnant women who have high education but who are also identified as having poor nutritional status. This may be due to the existence of health behaviors that are formed from various factors that work together, so that even though a person has higher education, his health behavior may be lacking (Leininger, 2002).

Limitation of the study: Research on the dimensions of transcultural nursing and nutritional status of pregnant women was carried out in a crosssectional approach, only describing a momentary state. The number of samples for validity and reliability testing was 21 pregnant women. As the mid-upper arm circumference is an indicator of nutritional status anthropometry., the change in MUAC measurement results is usually very small and measured over a long time, thus reflecting chronic nutritional status

\section{CONCLUSION}

The nutritional status of pregnant women is reviewed based on the theory of transcultural nursing related to the factors of technology utilization, family support, cultural values, knowledge about politics \& legal, family economics, and education of pregnant women but there is no relationship with the factor of religiosity. Pregnant women who can take advantage of technology, get optimal family support, positive cultural negotiations, good legal political understanding, economic status and adequate education will be able to maintain good nutritional status during pregnancy.

Further research on the nutritional status of pregnant women needs to be carried out longitudinally by measuring the pregnant woman's weight and blood hemoglobin levels. The government needs to increase awareness in preventing and overcoming nutritional problems in pregnant women by considering the existing culture in society.

\section{REFERENCES}

Adams, K. P., Lybbert, T. J., Vosti, S. A., Ayifah, E., Arimond, M., Adu-Afarwuah, S., \& Dewey, K. G. (2018). Unintended effects of a targeted maternal and child nutrition intervention on household expenditures, labor income, and the nutritional status of non-targeted siblings in Ghana. World Development, 107, 138-150. https://doi.org/10.1016/j.worlddev.2018.02.025

Alit Armini, N. K., Tristiana, R. D., \& Ose Tokan, A. (2017). Husband's Support is Needed to Prevent Postpartum Depression. 3(Inc), 4-7. https://doi.org/10.2991/inc-17.2017.7

Bhutta, Z. A., Ahmed, T., Black, R. E., Cousens, S., Dewey, K., Giugliani, E., ... Shekar, M. (2008). What works? Interventions for maternal and child undernutrition and survival. The Lancet, 371(9610), 417-440. https://doi.org/10.1016/S0140-6736(07)616936

Blondin, J. H., \& LoGiudice, J. A. (2018). Pregnant women's knowledge and awareness of nutrition. Applied Nursing Research. https://doi.org/10.1016/j.apnr.2017.11.020

Chakona, G., \& Shackleton, C. (2019). Food Taboos and Cultural Beliefs Influence Food Choice and Dietary Preferences among Pregnant. Nutrients, 11,1-18.

Chandra, F., Junita, D., \& Fatmawati, T. Y. (2019). Tingkat Pendidikan dan Pengetahuan Ibu Hamil dengan Status Anemia. Jurnal Ilmiah Ilmu Keperawatan Indonesia, 9(04), 653-659. https://doi.org/10.33221/jiiki.v9i04.398

Demelash, H., Id, D., \& Dadi, A. F. (2019). Burden and determinants of malnutrition among pregnant women in Africa: A systematic review and metaanalysis. Journal PLoS ONE, 14(9), 1-19. https://doi.org/https://doi.org/10.1371/journal. pone.0221712

Diamond-Smith, N. G., Gupta, M., Kaur, M., \& Kumar, R. (2016). Determinants of Persistent Anemia in Poor, Urban Pregnant Women of Chandigarh City, North India. Food and Nutrition Bulletin, 37(2), 132-143. https://doi.org/10.1177/0379572116637721

Diana, R., Khomsan, A., Anwar, F., Christianti, D. F., Kusuma, R., \& Rachmayanti, R. D. (2019). Dietary Quantity and Diversity among Anemic Pregnant Women in Madura Island, Indonesia. Journal of Nutrition and Metabolism, 2019. https://doi.org/10.1155/2019/2647230

Fitriani, A. (2016). Peran Religiusitas Dalam Meningkatkan Psychological Well Being. Al-Adyan, 11(1), 57-80. https://doi.org/https://doi.org/10.24042/ajsla.v $11 \mathrm{i} 1.1437$

Hundera, T., Wirtu, D., Gemede, H., \& Kenie, D. (2015). Nutritional Status and Associated Factors Among Lactating Mothers in Nekemte Referral Hospital and Health Centers, Ethiopia. International Journal of Nutrition and Food Sciences, 4(2), 216. https://doi.org/10.11648/j.ijnfs.20150402.23 
Ipa, M., Prasetyo, D. A., \& Kasnodihardjo. (2016). Praktik budaya perawatan dalam kehamilan persalinan dan nifas pada etnik baduy dalam. (April), 25-36.

Islam, A., Islam, N., Bharati, P., Aik, S., \& Hossain, G. (2016). Socio-economic and demographic factors influencing nutritional status among early childbearing young mothers in Bangladesh. $B M C$ Women's Health, 16(58), 1-9. https://doi.org/10.1186/s12905-016-0338-y

Kemenkes. (2017). HASIL PEMANTAUAN STATUS GIZI (PSG) TAHUN 2016.

Krishnaswamy, K. (2001). Perspectives on Nutrition Needs for the New Millennium for South Asian Regions. Biomedical and Environmental Sciences, 14(1-2), 66-74.

Lee, A., Newton, M., Radcliffe, J., \& Belski, R. (2018). Pregnancy nutrition knowledge and experiences of pregnant women and antenatal care clinicians: A mixed methods approach. Women and Birth, 31(4),

269-277. https://doi.org/10.1016/j.wombi.2017.10.010

Leininger, M., \& Mcfarland, M. R. (2002). Transcultural Nursing: Concepts, Theories, Research \& Practice (Third Edit). United States of America: The McGraw-Hill Companies.

Muttaqin, A. (2018). Analisis Faktor yang Berhubungan dengan Status Gizi Balita Berdasarkan Teori Transcultural Nursing di Desa Srowo Kecamatan Sidayu Kabupaten Gresik. Skripsi Fakultas Keperawatan Universitas Airlangga.

Nurdin, M. S., Hadju, V., Ansariadi, Zulkifli, A., \& Arundhana, A. I. (2018). Determinants of anaemia among pregnant women in jeneponto regency. Pakistan Journal of Medical and Health Sciences, 12(1), 429-434.

Parmar, A., Khanpara, H., Kartha, G., Resident, P. G., \& Shah, C. U. (2013). A study on taboos and misconceptions associated with pregnancy among rural women of Surendranagar district 1. 4(2), 2-5. Renjani, R. S., \& Misra. (2017). Faktor-Faktor yang Berhubungan dengan Kejadian Kekurangan Energi Kronis ( KEK ) pada Ibu Hamil di Wilayah Kerja Puskesmas Krueng Barona Jaya Kabupaten Aceh Besar. Journal of Healthcare Technology and Medicine, 3(2), 254-270. https://doi.org/https://doi.org/10.33143/jhtm.v 3i2.416

Rubina Shaheen, L. L. (2016). Quality of life among pregnant women with chronic energy deficiency in rural Bangladesh. Health Policy, 78(2-3), 128134.

Serbesa, M. L., Iffa, M. T., \& Geleto, M. (2019). Factors associated with malnutrition among pregnant women and lactating mothers in Miesso Health Center , Ethiopia. European Journal of Midwifery, $1-5$. https://doi.org/https://doi.org/10.18332/ejm/1 10131

Triharini, M., Armini, N. K. A., \& Nastiti, A. A. (2018). Effect of Educational Intervention on Family Support for Pregnant Women in Preventing Anemia. Belitung Nursing Journal, 4(3), 304-311. https://doi.org/10.33546/bnj.332

Triharini, M., Nursalam, Sulistyono, A., Adriani, M., Armini, N. K. A., \& Nastiti, A. A. (2018). Adherence to iron supplementation amongst pregnant mothers in Surabaya, Indonesia: Perceived benefits, barriers and family support. International Journal of Nursing Sciences, 5(3), 243-248. https://doi.org/10.1016/j.ijnss.2018.07.002

Yunitasari, E., Pradanie, R., \& Susilawati, A. (2016). Early Marriage Based on Transcultural Nursing Theory in Kara Village Sampang. Jurnal Ners, 11(2015), 164-169. https://doi.org/10.20473/JN.V11I22016.164169 